\title{
DNA Barcoding of Marine Mollusks Associated with Corallina officinalis Turfs in Southern Istria (Adriatic Sea)
}

\author{
Moira Buršić ${ }^{1}$, Ljiljana Iveša ${ }^{2}$ (D) Andrej Jaklin ${ }^{2}$, Milvana Arko Pijevac ${ }^{3}$, Mladen Kučinić ${ }^{4}$, Mauro Štifanić ${ }^{1}$, \\ Lucija Neal ${ }^{5}$ and Branka Bruvo Mađarić ${ }^{6, *}$ \\ 1 Faculty of Natural Sciences, Juraj Dobrila University of Pula, Zagrebačka 30, 52100 Pula, Croatia; \\ moira.bursic@unipu.hr (M.B.); mauro.stifanic@unipu.hr (M.Š.) \\ 2 Center for Marine Research, Ruđer Bošković Institute, G. Paliage 5, 52210 Rovinj, Croatia; \\ ivesa@cim.irb.hr (L.I.); jaklin@cim.irb.hr (A.J.) \\ 3 Natural History Museum Rijeka, Lorenzov Prolaz 1, 51000 Rijeka, Croatia; milvana@prirodoslovni.com \\ 4 Department of Biology, Faculty of Science, University of Zagreb, Rooseveltov trg 6, 10000 Zagreb, Croatia; \\ kucinic@biol.pmf.hr \\ 5 Kaplan International College, Moulsecoomb Campus, University of Brighton, Watts Building, Lewes Rd., \\ Brighton BN2 4GJ, UK; lucija.neal@kaplan.com \\ 6 Molecular Biology Division, Ruđer Bošković Institute, Bijenička 54, 10000 Zagreb, Croatia \\ * Correspondence: branka.bruvo.madjaric@irb.hr
}

Citation: Buršić, M.; Iveša, L.; Jaklin, A.; Arko Pijevac, M.; Kučinić, M.; Štifanić, M.; Neal, L.; Mađarić, B.B. DNA Barcoding of Marine Mollusks Associated with Corallina officinalis Turfs in Southern Istria (Adriatic Sea). Diversity 2021, 13, 196. https:/ /doi. org $/ 10.3390 / \mathrm{d} 13050196$

Academic Editor: Gert Wörheide

Received: 1 March 2021

Accepted: 29 April 2021

Published: 30 April 2021

Publisher's Note: MDPI stays neutral with regard to jurisdictional claims in published maps and institutional affiliations.

Copyright: (c) 2021 by the authors. Licensee MDPI, Basel, Switzerland. This article is an open access article distributed under the terms and conditions of the Creative Commons Attribution (CC BY) license (https:/ / creativecommons.org/licenses/by/ $4.0 /)$.

\begin{abstract}
Presence of mollusk assemblages was studied within red coralligenous algae Corallina officinalis L. along the southern Istrian coast. C. officinalis turfs can be considered a biodiversity reservoir, as they shelter numerous invertebrate species. The aim of this study was to identify mollusk species within these settlements using DNA barcoding as a method for detailed identification of mollusks. Nine locations and 18 localities with algal coverage range above $90 \%$ were chosen at four research areas. From 54 collected samples of $C$. officinalis turfs, a total of 46 mollusk species were identified. Molecular methods helped identify 16 gastropod, 14 bivalve and one polyplacophoran species. COI sequences for two bivalve species (Musculus cf. costulatus (Risso, 1826) and Gregariella semigranata (Reeve, 1858)) and seven gastropod species (Megastomia winfriedi Peñas \& Rolán, 1999, Eatonina sp. Thiele, 1912, Eatonina cossurae (Calcara, 1841), Crisilla cf. maculata (Monterosato, 1869), Alvania cf. carinata (da Costa, 1778), Vitreolina antiflexa (Monterosato, 1884) and Odostomia plicata (Montagu, 1803)) represent new BINs in BOLD database. This study contributes to new findings related to the high biodiversity of mollusks associated with widespread C. officinalis settlements along the southern coastal area of Istria.
\end{abstract}

Keywords: mollusks; gastropods; bivalves; Corallina officinalis; molecular identification; DNA barcoding; Adriatic Sea

\section{Introduction}

Corallina officinalis L. is an encrusting red alga, globally widely distributed in the temperate zone where it forms dense settlements in the intertidal area. It modifies the environment through its characteristic structure and is an ideal example of how algae affect the composition and interaction of organisms within their settlements [1]. It shelters many macrofaunal groups from wave action, predation, and stress from desiccation in the intertidal area [2-4]. Based on the mapping results of its habitats along the eastern Adriatic coast [5], the coastal area of the Adriatic Sea is a suitable location for Corallina's settlements. Looking on a smaller scale, along the western Istrian coast, the same continuous widespread distribution is recorded for Corallina officinalis and Ellisolandia elongata (J.Ellis \& Solander) K.R.Hind \& G.W.Saunders, with C. officinalis dominating in areas with no anthropogenic impact [6].

Changes in the structure and composition of macrofauna found in C. officinalis turfs have been studied worldwide [2,7-11]. All previous data showed high abundance and 
variety of invertebrates present. The most common taxonomic groups found were polychaetes, crustaceans (amphipods, isopods, tanaidaceans, decapods), pycnogonids and mollusks, mostly represented by bivalves and gastropods [2,8,12-24]. Notably, most of the invertebrate specimens recorded in C. officinalis turfs were present as juvenile stages, making the identification according to morphological features very complex $[2,8,12-24]$.

DNA barcoding [25] can be very useful in identifying specific taxonomic groups or developmental stages of various invertebrates in situations where species determination based on morphology is extremely problematic $[26,27]$, as well as in cases where a damaged organism is present or just a tissue fragment is available [28]. DNA barcoding of marine organisms has been ongoing around the world for more than a decade to distinguish cryptic and invasive species as well as to help explain different puzzling life cycles, making it a convenient tool for assessment and conservation of marine biodiversity [29-32]. However, it has not yet been used in studies of invertebrate fauna within C. officinalis turfs, and this paper presents how sequence data of the mitochondrial cox-1 gene (i.e., the barcode region, mtDNA COI-5P) can be used to confirm or eventually correct morphological identifications for such problematic specimens. Additionally, this study is one of the first examples of barcode methodology usage for Croatian marine mollusks. We further highlight the importance of molecular methods in marine invertebrates identification and supplementing existing DNA barcode databases such as BOLD database with valid sequence data.

\section{Materials and Methods}

The research was carried out in the northeastern part of the Adriatic Sea, in the coastal area of southern Istria and Brijuni National Park. Intertidal area of southern Istria is dominated by carbonate sedimentary rocks which represents a desirable substrate type for the settlements of the red alga Corallina officinalis [33]. Sampling was performed in the summer period of 2018, between June and August, in four different sampling areas named Pula, Banjole, Premantura and NP Brijuni (Brijuni National Park). Each sampling area had two or, in case of NP Brijuni, three sampling localities with a total of nine sampling locations indicated in Figure 1.

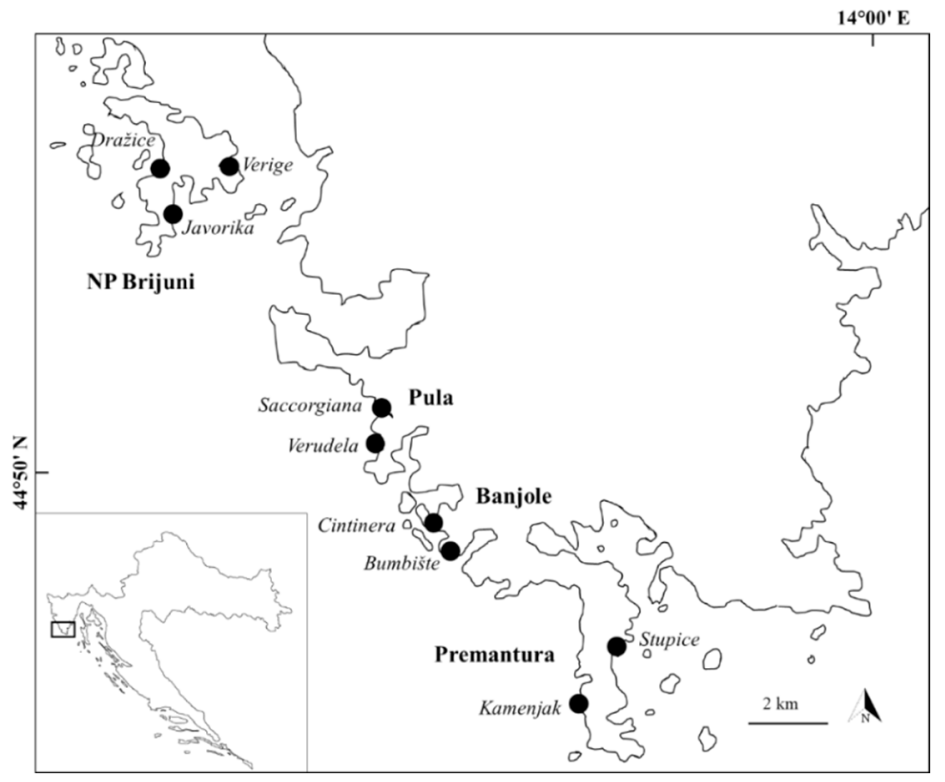

Figure 1. Sampling locations (in italics) within four areas (Pula, Banjole, Premantura, NP Brijuni) situated in southern Istria.

Prior to sampling of C. officinalis, mapping of its presence along the southern Istrian coast was performed. The density of the algae settlement was estimated based on the percentage of algal coverage in the coastal belt about $50 \mathrm{~cm}$ wide and the algal coverage for 
all sampling localities chosen was above $90 \%$. Algae sampling was performed quantitatively by scraping off with a hammer and chisel within three randomly positioned replicate quadrats $5 \times 5 \mathrm{~cm}$ in size. A total of 54 samples were collected and analyzed. In order to prevent and reduce the loss of mollusks associated with the red algae, sampling was performed during low tide while the algae were completely out of water. Algae samples were rinsed in the laboratory using a $500 \mu \mathrm{m}$ mesh size sieve and each branch was carefully inspected under a stereomicroscope. Mollusks were sorted, counted and identified to the lowest possible taxonomic rank based on morphology according to available literature [34-42]. Morphological identifications were conducted by taxonomists specialized for marine mollusks, particularly bivalves and gastropods, and specimens were compared with the marine mollusks collection of the Natural History Museum Rijeka (Croatia). After identification, each specimen was preserved in $96 \%$ ethanol for further processing. The World Register of Marine Species was used to check all species names [43]. Since identification according to morphological features was not possible for some specimens, DNA barcoding was implemented.

Mollusks that were sampled from C. officinalis turfs were only a couple of millimeters in size, so genomic DNA was extracted from the entire specimen using the QIAamp DNA Micro Kit, according to the manufacturer's specifications. Another specimen from the same sampling location and with the same morphological characteristics was kept as a paravoucher in the Invertebrates DNA Barcode collection of the Juraj Dobrila University of Pula. Elution was done in two stages, first with $50 \mu \mathrm{L}$ elution buffer and second with $100 \mu \mathrm{L}$ elution buffer. NanoDrop spectrophotometer was used to check the quantity of extracted DNA.

Full-length COI-5P DNA barcodes were amplified using primer sets LCO1490/ HCO2198 [44] and jgLCO1490/jgHCO2198 [45]. Even though additional primer sets were initially tested [46,47], all DNA barcodes were successfully amplified with the use of jgLCO1490/jgHCO2198 primer set with the exception of the specimens identified as Mytilus galloprovincialis which were amplified with LCO1490/HCO2198 primer set. $20 \mu \mathrm{L}$ polymerase chain reactions (PCR) mixture contained $1 \times$ DreamTaq $^{\mathrm{TM}}$ Reaction Buffer (containing $2 \mathrm{mM} \mathrm{MgCl}$, Thermo Scientific, Waltham, Massachusetts, USA), $0.2 \mathrm{mM} \mathrm{dNTP}$ mix (Qiagen), $0.5 \mu \mathrm{M}$ of each primer, 1.0 U DreamTaq polymerase (Thermo Scientific) and $3 \mu \mathrm{L}$ of DNA eluate (10-fold dilution of the second eluate). PCR cycling conditions comprised an initial denaturation step $\left(95^{\circ} \mathrm{C}\right.$ for $1 \mathrm{~min}$ ) followed by 35 cycles of denaturation at $95{ }^{\circ} \mathrm{C}$ for $45 \mathrm{~s}$, annealing at $48{ }^{\circ} \mathrm{C}$ for $45 \mathrm{~s}$ and elongation at $72{ }^{\circ} \mathrm{C}$ for $45 \mathrm{~s}$ and a final extension step at $72{ }^{\circ} \mathrm{C}$ for $7 \mathrm{~min}$. Quality and quantity of PCR products were checked by electrophoresis on 1\% agarose gel stained with ethidium bromide. Enzymatic cleanup of PCR products was done using Exonuclease I and Antarctic Phosphatase (AnP) according to the manufacturer's specifications (New England BioLabs-NEB). Bidirectional sequencing was performed by Macrogen Inc. sequencing service (Amsterdam, Netherlands) using the same amplification primers as for the PCR reaction. Sequences were edited and curated using the programs BioEdit v.7.0.5.3. [48] and Geneious Prime v.11.0.3 + 7 (http://www.geneious.com, accessed on 10 January 2021) [49]. EMBOSS Sixpack (https://www.ebi.ac.uk/Tools/st/emboss_sixpack/, accessed on 25 January 2021) [50] was used to check the open reading frame. All DNA sequences were submitted to both the Barcode of Life Data Systems_-BOLD [51] and NCBI GenBank [52]. BOLD Process IDs, GenBank Accession numbers and Inventory numbers are given in Table S1.

BOLD identification tool (http://www.boldsystems.org/index.php/IDS_OpenIdEngine, accessed on 10 February 2021) and BLAST (https:/ /blast.ncbi.nlm.nih.gov/Blast.cgi, accessed on 10 February 2021) were used for initial comparison of obtained DNA sequences with sequences available in BOLD and NCBI databases and their classification into putative species or higher taxonomic categories, depending on the obtained genetic distances (Kimura-2-P, K2P, calculated in MEGA-X v.10.0.5 [53]. A threshold of 3\% was considered as the most commonly used cut-off value for species designations for marine mollusks [54-57], while for the specimens with lower similarities a tree-based identification in BOLD was 
performed (Taxon ID NJ tree tool; K2P distances; pairwise deletion) so that the specimen could be classified into a genus, family or higher taxonomic rank.

Several algorithms were employed to assign specimens to particular species (i.e., operational taxonomic units, OTUs). Firstly, Barcode Index Numbers (BINs) were allocated to specimens using REfined Single Linkage Analysis (RESL) in BOLD [58]. In addition, species delineation methods (SDMs) bPTP [59] (https://species.h-its.org/ptp/, accessed on 22 March 2021), ASAP [60] (https:/ / bioinfo.mnhn.fr/abi/public/asap/asapweb.html, accessed on 22 March 2021) and ABGD [61] (https:/ /bioinfo.mnhn.fr/abi/public/abgd/, accessed on 22 March 2021) (all under default parameters) were performed to confirm the initial classification of specimens. Depending on the availability of data, datasets used in species delineations consisted of conspecific, congeneric and/or confamiliar sequences withdrawn from BOLD database of public records. MAFFT v.7 [62] (https: / / mafft.cbrc.jp/alignment/server/index.html, accessed on 24 March 2021) was used for multiple nucleotide sequence alignments (alignment datasets in Supplementary File S2). As input for bPTP, maximum likelihood (ML) trees were constructed on PhyML 3.0 webserver [63] (http:/ / www.atgc-montpellier.fr/phyml/, accessed on 25 March 2021), with automatic model selection by SMS determined through AIC selection criterion [64] (ML trees in Supplementary File S3).

The final decision for each specimen identification was made by taking into consideration a combination of morphological features, BLAST and BOLD similarity results, BIN-RESL assignments and the results of SDMs.

\section{Results}

A total of 14,757 individual mollusks were isolated from C. officinalis turfs collected along the southern Istrian coast and identified to the species level wherever possible. Identification according to their morphological features resulted in 46 species, of which 26 gastropods, 19 bivalves and one polyplacophoran (Tables 1 and 2). Detailed information about species distribution for each investigated sampling location are being prepared for publication in a separate article. For $69 \%$ of specimens subjected to DNA barcoding, COI-barcode region was successfully amplified. Out of 54 mitochondrial cox- 1 sequences obtained, 24 sequences belonged to gastropods, 29 sequences to bivalves and one sequence to a polyplacophoran. Certain species were represented with more than one specimen which was confirmed with additional analyses such as calculation of inter- and intraspecific genetic p-distances of the mitochondrial cytochrome oxidase I gene fragments (Tables S4-S6) as well as BIN-RESL, bPTP, ASAP and ABGD species delineation methods (SDMs) (Table 1). As a result of these analyses, the number of species recorded through DNA barcoding adds up to 31 (16 species for gastropods, 14 species for bivalves and one polyplacophoran). Several individuals were not successfully barcoded, so the total number of barcoded species is $33 \%$ lower than the number of species recorded based on morphological features ( 31 barcoded species compared to 46 morphologically identified species). 
Table 1. Sequenced mollusks and their identification according to morphological features and DNA barcoding. AD: Average BIN Distance; DNN: Distance to Nearest Neighbor. Specimens classified in OTUs as recovered by species delimitation methods-A: OTU separate from all other BOLD entries and no additional OTUs with conspecific entries (as entered in BOLD); B: OTU separate from all other BOLD entries but there are also additional OTUs with conspecific entries; C: OTU composed of conspecific BOLD entries and there are no additional OTUs with conspecific entries; D: OTU composed of conspecific BOLD entries and there are additional OTUs with conspecific entries; E: OTU composed of conspecific BOLD entries and other morpho-species (discordant OTU); n.a.: species delimitation analyses were not performed since there are no confamiliar sequences in BOLD.

\begin{tabular}{|c|c|c|c|c|c|c|}
\hline $\begin{array}{l}\text { Morphological } \\
\text { Determination } \\
\text { (Family) }\end{array}$ & $\begin{array}{l}\text { BOLD ID/BLAST Hit } \\
\text { (Family; \% Similarity) }\end{array}$ & $\begin{array}{c}\text { BIN-RESL } \\
\text { (AD/DNN \%) }\end{array}$ & bPTP & ABGD & ASAP & $\begin{array}{l}\text { SPECIES Submitted to BOLD } \\
\text { (Family)/BOLD Process ID }\end{array}$ \\
\hline $\begin{array}{l}\text { GASTROPODA } \\
\begin{array}{l}\text { Bittium reticulatum } \\
\text { (Cerithiidae) }\end{array}\end{array}$ & $\begin{array}{l}\text { Bittium reticulatum } \\
\text { (Cerithiidae; } 95.59 \text { ) }\end{array}$ & $\begin{array}{l}\text { BOLD:ACV9171 } \\
(1.77 / 2.52)\end{array}$ & B & $\mathrm{C}$ & B & $\begin{array}{l}\text { Bittium reticulatum } \\
\text { (Cerithiidae)/CROMI001-19 }\end{array}$ \\
\hline $\begin{array}{l}\text { Eatonina sp. juv. } \\
\text { (Cingulopsidae) }\end{array}$ & $\begin{array}{l}\text { Sassia bassi } \\
\text { (Cymatiidae; } 83.28 \text { ) } \\
\text { Amphissa reticulata } \\
\text { (Columbellidae; } 83.26 \text { ) }\end{array}$ & $\begin{array}{l}\text { BOLD:AEA4980* } \\
\text { (N/A/16.69) }\end{array}$ & n.a. & n.a. & n.a. & $\begin{array}{l}\text { ** Eatonina sp. } \\
\text { (Cingulopsidae)/ } \\
\text { CROMI010-19 }\end{array}$ \\
\hline $\begin{array}{l}\text { Eatonina cossurae } \\
\text { (Cingulopsidae) }\end{array}$ & $\begin{array}{l}\text { Crepidula convexa } \\
\text { (Calyptraeidae; 82.07) } \\
\text { Fluminicola sp. } \\
\text { (Hydrobiidae; 82.19) }\end{array}$ & $\begin{array}{l}\text { BOLD:AEA4781* } \\
\text { (N/A/17.98) }\end{array}$ & n.a. & n.a. & n.a. & $\begin{array}{l}\text { ** Eatonina cossurae } \\
\text { (Cingulopsidae)/ } \\
\text { CROMI057-19 }\end{array}$ \\
\hline $\begin{array}{l}\text { Vitreolina antiflexa } \\
\text { (Eulimidae) }\end{array}$ & $\begin{array}{l}\text { cf. Crinolamia sp. } \\
\text { (Eulimidae; } 80.27 \text { ) }\end{array}$ & $\begin{array}{l}\text { BOLD:AEA6078* } \\
\text { (N/A/16.53) }\end{array}$ & $\mathrm{A}$ & $\mathrm{A}$ & $\mathrm{A}$ & $\begin{array}{l}{ }^{* *} \text { Vitreolina antiflexa } \\
\text { (Eulimidae)/ } \\
\text { CROMI044-19 }\end{array}$ \\
\hline $\begin{array}{l}\text { cf. Episcomitra } \\
\text { cornicula juv. } \\
\text { (Mitridae) }\end{array}$ & $\begin{array}{l}\text { Episcomitra cornicula } \\
\text { (Mitridae; } 98.48 \text { ) }\end{array}$ & $\begin{array}{l}\text { BOLD:ACT4873 } \\
(1.8 / 7.01)\end{array}$ & $\mathrm{C}$ & $\mathrm{C}$ & $\mathrm{C}$ & $\begin{array}{l}\text { Episcomitra cornicula } \\
\text { (Mitridae)/ } \\
\text { CROMI043-19 }\end{array}$ \\
\hline $\begin{array}{l}\text { Muricopsis cristata juv. } \\
\text { (Muricidae) }\end{array}$ & $\begin{array}{l}\text { Ocenebra cf. edwardsii } \\
\text { (Muricidae; 100.00) }\end{array}$ & $\begin{array}{l}\text { BOLD:ACF7365 } \\
(0.19 / 4.98)\end{array}$ & $\mathrm{D}$ & $\mathrm{D}$ & $\mathrm{D}$ & $\begin{array}{l}\text { Ocenebra cf. edwardsii } \\
\text { (Muricidae)/ } \\
\text { CROMI059-19 }\end{array}$ \\
\hline $\begin{array}{l}\text { Patella cf. caerulea juv. } \\
\text { (Patellidae) }\end{array}$ & $\begin{array}{l}\text { Patella caerulea } \\
\text { (Patellidae; 99.56) }\end{array}$ & $\begin{array}{l}\text { BOLD:AAC1245 } \\
(0.32 / 4.74)\end{array}$ & $\mathrm{C}$ & $\mathrm{C}$ & $\mathrm{C}$ & $\begin{array}{l}\text { Patella caerulea (Patellidae)/ } \\
\text { CROMI046-19 }\end{array}$ \\
\hline $\begin{array}{l}\text { Megastomia winfriedi } \\
\text { juv. (Pyramidellidae) }\end{array}$ & $\begin{array}{l}\text { Odostomia } \\
\text { (Pyramidellidae; 83.64) } \\
\text { Boonea cincta } \\
\text { (Pyramidellidae; 83.09) }\end{array}$ & $\begin{array}{l}\text { BOLD:AEA7694 * } \\
(0.81 / 15.12)\end{array}$ & $\mathrm{A}$ & $\mathrm{A}$ & $\mathrm{A}$ & $\begin{array}{l}{ }^{* *} \text { Megastomia winfriedi } \\
\text { (Pyramidellidae)/CROMI008- } \\
19\end{array}$ \\
\hline $\begin{array}{l}\text { Megastomia winfriedi } \\
\text { juv. (Pyramidellidae) }\end{array}$ & $\begin{array}{l}\text { Odostomia } \\
\text { (Pyramidellidae; } 82.17 \text { ) }\end{array}$ & $\begin{array}{c}\text { BOLD:AEA7694* } \\
(0.81 / 15.12)\end{array}$ & A & A & $\mathrm{A}$ & $\begin{array}{l}{ }^{* *} \text { Megastomia winfriedi } \\
\text { (Pyramidellidae)/CROMI061- } \\
19\end{array}$ \\
\hline $\begin{array}{l}\text { Odostomia plicata } \\
\text { (Pyramidellidae) }\end{array}$ & (Pyramidellidae; 73.12) & $\begin{array}{l}\text { BOLD:AEA6873* } \\
\text { (N/A/25.65) }\end{array}$ & A & A & $\mathrm{A}$ & $\begin{array}{l}\text { ** Odostomia plicata } \\
\text { (Pyramidellidae)/CROMI048- } \\
19\end{array}$ \\
\hline $\begin{array}{l}\text { Rissoella sp. juv. } \\
\text { (Rissoellidae) }\end{array}$ & $\begin{array}{l}\text { Rissoella japonica } \\
\text { (Rissoellidae; 82.01) }\end{array}$ & $\begin{array}{l}\text { BOLD:AEA8121 * } \\
(1.99 / 17.55)\end{array}$ & $\mathrm{A}$ & A & A & $\begin{array}{l}\text { Rissoella sp. (Rissoellidae)/ } \\
\text { CROMI009-19 }\end{array}$ \\
\hline $\begin{array}{l}\text { Rissoella sp. juv. } \\
\text { (Rissoellidae) }\end{array}$ & $\begin{array}{l}\text { Rissoella japonica } \\
\text { (Rissoellidae; 82.36) }\end{array}$ & $\begin{array}{l}\text { BOLD:AEA8121* } \\
(1.99 / 17.55)\end{array}$ & $\mathrm{A}$ & A & A & $\begin{array}{l}\text { Rissoella sp. (Rissoellidae)/ } \\
\text { CROMI034-19 }\end{array}$ \\
\hline $\begin{array}{l}\text { cf. Alvania carinata juv. } \\
\text { (Rissoidae) }\end{array}$ & $\begin{array}{l}\text { Cerithium adustum } \\
\text { (Cerithiidae; } 84.87 \text { ) } \\
\text { Cerithium nodulosum } \\
\text { (Cerithiidae; 83.94) }\end{array}$ & $\begin{array}{l}\text { BOLD:AEA4597* } \\
\text { (N/A/15.57) }\end{array}$ & $\mathrm{A}$ & A & A & $\begin{array}{l}\text { ** Alvania cf. carinata } \\
\text { (Rissoidae)/CROMI041-19 }\end{array}$ \\
\hline $\begin{array}{l}\text { cf. Alvania discors juv. } \\
\text { (Rissoidae) }\end{array}$ & $\begin{array}{l}\text { Alvania angioyi } \\
\text { (Rissoidae; 86.70) } \\
\text { Cingula trifasciata } \\
\text { (Rissoidae; 86.35) } \\
\end{array}$ & $\begin{array}{l}\text { BOLD:AEA4635* } \\
\text { (N/A/13.48) }\end{array}$ & $\mathrm{A}$ & A & A & $\begin{array}{l}\text { Alvania sp. (Rissoidae)/ } \\
\text { CROMI045-19 }\end{array}$ \\
\hline $\begin{array}{l}\text { Crisilla maculata } \\
\text { (Rissoidae) }\end{array}$ & $\begin{array}{l}\text { Rissoella japonica } \\
\text { (Rissoellidae; 83.94) }\end{array}$ & $\begin{array}{l}\text { BOLD:AEA8121 * } \\
(1.99 / 17.55)\end{array}$ & A & A & A & $\begin{array}{l}\text { Rissoella sp. (Rissoellidae)/ } \\
\text { CROMI053-19 }\end{array}$ \\
\hline
\end{tabular}


Table 1. Cont.

\begin{tabular}{|c|c|c|c|c|c|c|}
\hline $\begin{array}{l}\text { Morphological } \\
\text { Determination } \\
\text { (Family) }\end{array}$ & $\begin{array}{l}\text { BOLD ID/BLAST Hit } \\
\text { (Family; \% Similarity) }\end{array}$ & $\begin{array}{c}\text { BIN-RESL } \\
(\text { AD/DNN \%) }\end{array}$ & bPTP & ABGD & ASAP & $\begin{array}{l}\text { SPECIES Submitted to BOLD } \\
\text { (Family)/BOLD Process ID }\end{array}$ \\
\hline $\begin{array}{l}\text { cf. Crisilla maculata } \\
\text { (Rissoidae) }\end{array}$ & $\begin{array}{l}\text { Setia turriculata } \\
\text { (Rissoidae; 88.06) }\end{array}$ & $\begin{array}{l}\text { BOLD:AEA7055 * } \\
(0.32 / 12.34)\end{array}$ & A & A & A & $\begin{array}{l}\text { ** Crisilla cf. maculata } \\
\text { (Rissoidae)/ } \\
\text { CROMI038-19 }\end{array}$ \\
\hline $\begin{array}{l}\text { cf. Crisilla maculata } \\
\text { (Rissoidae) }\end{array}$ & $\begin{array}{l}\text { Setia turriculata } \\
\text { (Rissoidae; 87.89) }\end{array}$ & $\begin{array}{l}\text { BOLD:AEA7055 * } \\
(0.32 / 12.34)\end{array}$ & A & A & A & $\begin{array}{l}{ }^{*} \text { Crisilla cf. maculata } \\
\text { (Rissoidae)/ } \\
\text { CROMI039-19 }\end{array}$ \\
\hline $\begin{array}{l}\text { Rissoidae indet. juv. } \\
\text { (Rissoidae) }\end{array}$ & $\begin{array}{l}\text { Rissoella japonica } \\
\text { (Rissoellidae; 83.20) }\end{array}$ & $\begin{array}{c}\text { BOLD:AEA8121 * } \\
(1.99 / 17.55)\end{array}$ & A & A & A & $\begin{array}{l}\text { Rissoella sp. (Rissoellidae)/ } \\
\text { CROMI060-19 }\end{array}$ \\
\hline $\begin{array}{l}\text { cf. Gibbula ardens juv. } \\
\text { (Trochidae) }\end{array}$ & $\begin{array}{l}\text { Gibbula turbinoides } \\
\text { (Trochidae; 96.47) }\end{array}$ & $\begin{array}{c}\text { BOLD:AEA5856 * } \\
(0.16 / 3.69)\end{array}$ & B & $\mathrm{D}$ & $\mathrm{D}$ & $\begin{array}{l}\text { Gibbula cf. turbinoides } \\
\text { (Trochidae)/ } \\
\text { CROMI042-19 }\end{array}$ \\
\hline $\begin{array}{l}\text { cf. Gibbula ardens juv. } \\
\text { (Trochidae) }\end{array}$ & $\begin{array}{l}\text { Steromphala adriatica } \\
\text { (Trochidae; } 99.68 \text { ) }\end{array}$ & $\begin{array}{c}\text { BOLD:ACA1591 } \\
(0.68 / 6.41)\end{array}$ & $\mathrm{E}$ & $\mathrm{E}$ & $\mathrm{E}$ & $\begin{array}{l}\text { Steromphala adriatica } \\
\text { (Trochidae)/ } \\
\text { CROMI040-19 }\end{array}$ \\
\hline $\begin{array}{l}\text { Gibbula turbinoides juv. } \\
\text { (Trochidae) }\end{array}$ & $\begin{array}{l}\text { Gibbula turbinoides } \\
\text { (Trochidae; 96.31) }\end{array}$ & $\begin{array}{c}\text { BOLD:AEA5856 * } \\
(0.16 / 3.69)\end{array}$ & B & $\mathrm{D}$ & $\mathrm{D}$ & $\begin{array}{l}\text { Gibbula cf. turbinoides } \\
\text { (Trochidae)/ } \\
\text { CROMI047-19 }\end{array}$ \\
\hline $\begin{array}{l}\text { Sinezona cingulata juv. } \\
\text { (Scissurellidae) }\end{array}$ & $\begin{array}{l}\text { Cochlostoma erika } \\
\text { (Megalomastomatidae; } \\
80.12 \text { ) } \\
\text { Bellamya robertsoni } \\
\text { (Viviparidae; } 80.00 \text { ) }\end{array}$ & $\begin{array}{l}\text { BOLD:AEA3659* } \\
(\mathrm{N} / \mathrm{A} / 19.26)\end{array}$ & A & A & A & $\begin{array}{l}\text { Gastropoda } \\
\text { CROMI007-19 }\end{array}$ \\
\hline $\begin{array}{l}\text { Phorcus turbinatus juv. } \\
\text { (Trochidae) }\end{array}$ & $\begin{array}{l}\text { Phorcus turbinatus } \\
\text { (Trochidae; 100.00) }\end{array}$ & $\begin{array}{c}\text { BOLD:ACB7685 } \\
(0.7 / 10.57)\end{array}$ & C & C & C & $\begin{array}{l}\text { Phorcus turbinatus (Trochidae)/ } \\
\text { CROMI002-19 }\end{array}$ \\
\hline $\begin{array}{l}\text { Phorcus turbinatus juv. } \\
\text { (Trochidae) }\end{array}$ & $\begin{array}{l}\text { Phorcus turbinatus } \\
\text { (Trochidae; } 100.00 \text { ) }\end{array}$ & $\begin{array}{l}\text { BOLD:ACB7685 } \\
(0.7 / 10.57)\end{array}$ & C & C & C & $\begin{array}{l}\text { Phorcus turbinatus (Trochidae)/ } \\
\text { CROMI058-19 }\end{array}$ \\
\hline $\begin{array}{l}\text { BIVALVIA } \\
\text { Arca tetragona juv. } \\
\text { (Arcidae) }\end{array}$ & $\begin{array}{l}\text { Striarca lactea } \\
\text { (Noetiidae; 98.62) } \\
\text { Arca tetragona } \\
\text { (Arcidae; 80.19) }\end{array}$ & $\begin{array}{l}\text { BOLD:ADK1293 } \\
(1.14 / 4.29)\end{array}$ & $\mathrm{D}$ & $\mathrm{D}$ & $\mathrm{D}$ & $\begin{array}{l}\text { Striarca lactea (Noetiidae)/ } \\
\text { CROMI011-19 }\end{array}$ \\
\hline $\begin{array}{l}\text { Carditidae indet. juv. } \\
\text { (Carditidae) }\end{array}$ & $\begin{array}{l}\text { Cardita calyculata } \\
\text { (Carditidae; 95.07) }\end{array}$ & $\begin{array}{c}\text { BOLD:AEA7765 * } \\
(0.75 / 5.07)\end{array}$ & B & C & C & $\begin{array}{l}\text { Cardita calyculata } \\
\text { (Carditidae)/ } \\
\text { CROMI017-19 }\end{array}$ \\
\hline $\begin{array}{l}\text { Carditidae indet. juv. } \\
\text { (Carditidae) }\end{array}$ & $\begin{array}{l}\text { Cardita calyculata } \\
\text { (Carditidae; 95.07) }\end{array}$ & $\begin{array}{c}\text { BOLD:AEA7765 * } \\
(0.75 / 5.07)\end{array}$ & B & C & C & $\begin{array}{l}\text { Cardita calyculata } \\
\text { (Carditidae)/ } \\
\text { CROMI018-19 }\end{array}$ \\
\hline $\begin{array}{l}\text { Carditidae indet. juv. } \\
\text { (Carditidae) }\end{array}$ & $\begin{array}{l}\text { Cardita calyculata } \\
\text { (Carditidae; 95.07) }\end{array}$ & $\begin{array}{c}\text { BOLD:AEA7765 * } \\
(0.75 / 5.07)\end{array}$ & B & C & C & $\begin{array}{l}\text { Cardita calyculata } \\
\text { (Carditidae)/ } \\
\text { CROMI019-19 }\end{array}$ \\
\hline $\begin{array}{l}\text { Carditidae indet. juv. } \\
\text { (Carditidae) }\end{array}$ & $\begin{array}{l}\text { Cardita calyculata } \\
\text { (Carditidae; 95.07) }\end{array}$ & $\begin{array}{c}\text { BOLD:AEA7765 * } \\
(0.75 / 5.07)\end{array}$ & B & C & C & $\begin{array}{l}\text { Cardita calyculata } \\
\text { (Carditidae)/ } \\
\text { CROMI020-19 }\end{array}$ \\
\hline $\begin{array}{l}\text { Carditidae indet. juv. } \\
\text { (Carditidae) }\end{array}$ & $\begin{array}{l}\text { Cardita calyculata } \\
\text { (Carditidae; 95.22) }\end{array}$ & $\begin{array}{c}\text { BOLD:AEA7765 * } \\
(0.75 / 5.07)\end{array}$ & B & C & C & $\begin{array}{l}\text { Cardita calyculata } \\
\text { (Carditidae)/ } \\
\text { CROMI027-19 }\end{array}$ \\
\hline $\begin{array}{l}\text { Carditidae indet. juv. } \\
\text { (Carditidae) }\end{array}$ & $\begin{array}{l}\text { Cardita calyculata } \\
\text { (Carditidae; } 95.38 \text { ) }\end{array}$ & $\begin{array}{c}\text { BOLD:AEA7765 * } \\
(0.75 / 5.07)\end{array}$ & B & C & C & $\begin{array}{l}\text { Cardita calyculata } \\
\text { (Carditidae)/ } \\
\text { CROMI035-19 }\end{array}$ \\
\hline $\begin{array}{l}\text { Lasaea adansoni juv. } \\
\text { (Lasaeidae) }\end{array}$ & $\begin{array}{l}\text { Lasaea rubra } \\
\text { (Lasaeidae; 94.83) }\end{array}$ & $\begin{array}{c}\text { BOLD:AEA6973* } \\
(\mathrm{N} / \mathrm{A} / 5.45)\end{array}$ & B & $\mathrm{E}$ & $\mathrm{E}$ & $\begin{array}{l}\text { Lasaea cf. rubra (Lasaeidae)/ } \\
\text { CROMI006-19 }\end{array}$ \\
\hline $\begin{array}{l}\text { Lucinella divaricata juv. } \\
\text { (Lucinidae) }\end{array}$ & $\begin{array}{l}\text { Lucinoma annulata } \\
\text { (Lucinidae; } 76.11 \text { ) }\end{array}$ & $\begin{array}{l}\text { BOLD:AEA7064 * } \\
(\mathrm{N} / \mathrm{A} / 23.76)\end{array}$ & A & A & A & $\begin{array}{l}\text { Lucinella sp. (Lucinidae)/ } \\
\text { CROMI016-19 }\end{array}$ \\
\hline $\begin{array}{l}\text { Gregariella semigranata } \\
\text { juv. } \\
\text { (Mytilidae) }\end{array}$ & $\begin{array}{l}\text { Mytilus edulis } \\
\text { (Mytilidae; 80.59) } \\
\text { Mytilus galloprovincialis } \\
\text { (Mytilidae; 79.56) }\end{array}$ & $\begin{array}{l}\text { BOLD:AEA7588* } \\
\text { (N/A/21.06) }\end{array}$ & A & A & A & $\begin{array}{l}* * \text { Gregariella semigranata } \\
\text { (Mytilidae)/ } \\
\text { CROMI062-19 }\end{array}$ \\
\hline
\end{tabular}


Table 1. Cont.

\begin{tabular}{|c|c|c|c|c|c|c|}
\hline $\begin{array}{l}\text { Morphological } \\
\text { Determination } \\
\text { (Family) }\end{array}$ & $\begin{array}{l}\text { BOLD ID/BLAST Hit } \\
\text { (Family; \% Similarity) }\end{array}$ & $\begin{array}{c}\text { BIN-RESL } \\
\text { (AD/DNN \%) }\end{array}$ & bPTP & ABGD & ASAP & $\begin{array}{l}\text { SPECIES Submitted to BOLD } \\
\text { (Family)/BOLD Process ID }\end{array}$ \\
\hline $\begin{array}{l}\text { Lithophaga litophaga } \\
\text { juv. } \\
\text { (Mytilidae) }\end{array}$ & $\begin{array}{l}\text { Lithophaga litophaga } \\
\text { (Mytilidae; 99.82) }\end{array}$ & $\begin{array}{l}\text { BOLD:AAX6397 } \\
(0.18 / 30.32)\end{array}$ & $\mathrm{C}$ & C & C & $\begin{array}{l}\text { Lithophaga litophaga } \\
\text { (Mytilidae)/ } \\
\text { CROMI013-19 }\end{array}$ \\
\hline $\begin{array}{l}\text { Musculus costulatus } \\
\text { juv. } \\
\text { (Mytilidae) }\end{array}$ & $\begin{array}{l}\text { Crenella faba } \\
\text { (Mytilidae; 74.96) } \\
\text { Musculus niger, M. discolor } \\
\text { (Mytilidae; 73.00) }\end{array}$ & $\begin{array}{l}\text { BOLD:AEA4861 * } \\
(0 / 13.53)\end{array}$ & B & B & B & $\begin{array}{l}\text { ** Musculus cf. costulatus } \\
\text { (Mytilidae)/ } \\
\text { CROMI003-19 }\end{array}$ \\
\hline $\begin{array}{l}\text { Musculus costulatus } \\
\text { juv. } \\
\text { (Mytilidae) }\end{array}$ & $\begin{array}{l}\text { Musculus costulatus } \\
\text { (Mytilidae; } 86.36 \text { ) }\end{array}$ & $\begin{array}{l}\text { BOLD:AEA4861 * } \\
(0 / 13.53)\end{array}$ & B & B & B & $\begin{array}{l}{ }^{* *} \text { Musculus cf. costulatus } \\
\text { (Mytilidae)/ } \\
\text { CROMI005-19 }\end{array}$ \\
\hline $\begin{array}{l}\text { Musculus sp. juv. } \\
\text { (Mytilidae) }\end{array}$ & $\begin{array}{l}\text { Musculus niger, } M . \text { discolor } \\
\text { (Mytilidae; } 74.00 \text { ) }\end{array}$ & $\begin{array}{l}\text { BOLD:AEA6766* } \\
(\mathrm{N} / \mathrm{A} / 4.62)\end{array}$ & A & A & A & $\begin{array}{l}\text { Musculus sp. (Mytilidae)/ } \\
\text { CROMI015-19 }\end{array}$ \\
\hline $\begin{array}{l}\text { Mytilaster minimus juv. } \\
\text { (Mytilidae) }\end{array}$ & $\begin{array}{l}\text { Mytilus galloprovincialis } \\
\text { (Mytilidae; 100.00) }\end{array}$ & $\begin{array}{c}\text { BOLD:AAA2184 } \\
(1.8 / 4.39)\end{array}$ & $\mathrm{D}, \mathrm{E}$ & $\mathrm{D}, \mathrm{E}$ & $\mathrm{D}, \mathrm{E}$ & $\begin{array}{l}\text { Mytilus galloprovincialis } \\
\text { (Mytilidae)/ } \\
\text { CROMI004-19 }\end{array}$ \\
\hline $\begin{array}{l}\text { Mytilaster sp. juv. } \\
\text { (Mytilidae) }\end{array}$ & $\begin{array}{l}\text { Mytilus galloprovincialis } \\
\text { (Mytilidae; 99.17) }\end{array}$ & $\begin{array}{c}\text { BOLD:AAA2184 \# } \\
(1.8 / 4.39)\end{array}$ & $\mathrm{D}, \mathrm{E}$ & $\mathrm{D}, \mathrm{E}$ & $\mathrm{D}, \mathrm{E}$ & $\begin{array}{l}\text { Mytilus galloprovincialis } \\
\text { (Mytilidae)/ } \\
\text { CROMI052-19 }\end{array}$ \\
\hline $\begin{array}{l}\text { Mytilus } \\
\text { galloprovincialis juv. } \\
\text { (Mytilidae) }\end{array}$ & $\begin{array}{l}\text { Mytilus galloprovincialis } \\
\text { (Mytilidae; 100.00) }\end{array}$ & $\begin{array}{c}\text { BOLD: AAA2184 }{ }^{\#} \\
(1.8 / 4.39)\end{array}$ & $\mathrm{D}, \mathrm{E}$ & $\mathrm{D}, \mathrm{E}$ & $\mathrm{D}, \mathrm{E}$ & $\begin{array}{l}\text { Mytilus galloprovincialis } \\
\text { (Mytilidae)/ } \\
\text { CROMI056-19 }\end{array}$ \\
\hline $\begin{array}{l}\text { Ostrea sp. juv. } \\
\text { (Chamidae) }\end{array}$ & $\begin{array}{l}\text { Chama gryphoides } \\
\text { (Chamidae; 98.85) }\end{array}$ & $\begin{array}{l}\text { BOLD:AAW6880 } \\
\quad(0.16 / 22.17)\end{array}$ & C & C & C & $\begin{array}{l}\text { Chama gryphoides (Chamidae)/ } \\
\text { CROMI014-19 }\end{array}$ \\
\hline $\begin{array}{l}\text { Veneridae indet. } 1 \text { juv. } \\
\text { (Veneridae) }\end{array}$ & $\begin{array}{l}\text { Austrovenus stutchburyi } \\
\text { (Veneridae; 82.98) }\end{array}$ & $\begin{array}{l}\text { BOLD:AEA5297* } \\
(1.09 / 18.26)\end{array}$ & A & A & A & $\begin{array}{l}\text { Veneridae } \\
\text { CROMI012-19 }\end{array}$ \\
\hline $\begin{array}{l}\text { Veneridae indet. } 1 \text { juv. } \\
\text { (Veneridae) }\end{array}$ & $\begin{array}{l}\text { Austrovenus stutchburyi } \\
\text { (Veneridae; 82.86) }\end{array}$ & $\begin{array}{c}\text { BOLD:AEA5297 * } \\
(1.09 / 18.26)\end{array}$ & A & A & A & $\begin{array}{l}\text { Veneridae } \\
\text { CROMI029-19 }\end{array}$ \\
\hline $\begin{array}{l}\text { Veneridae indet. } 1 \text { juv. } \\
\text { (Veneridae) }\end{array}$ & $\begin{array}{l}\text { Austrovenus stutchburyi } \\
\text { (Veneridae; 82.83) }\end{array}$ & $\begin{array}{c}\text { BOLD:AEA5297* } \\
(1.09 / 18.26)\end{array}$ & A & A & A & $\begin{array}{l}\text { Veneridae } \\
\text { CROMI030-19 }\end{array}$ \\
\hline $\begin{array}{l}\text { Veneridae indet. } 2 \text { juv. } \\
\text { (Veneridae) }\end{array}$ & $\begin{array}{l}\text { Austrovenus stutchburyi } \\
\text { (Veneridae; 82.74) }\end{array}$ & $\begin{array}{c}\text { BOLD:AEA5058 * } \\
(0.44 / 17.18)\end{array}$ & A & A & A & $\begin{array}{l}\text { Veneridae } \\
\text { CROMI021-19 }\end{array}$ \\
\hline $\begin{array}{l}\text { Veneridae indet. } 2 \text { juv. } \\
\text { (Veneridae) }\end{array}$ & $\begin{array}{l}\text { Austrovenus stutchburyi } \\
\text { (Veneridae; 83.74) }\end{array}$ & $\begin{array}{l}\text { BOLD:AEA5058 * } \\
(0.44 / 17.18)\end{array}$ & A & A & A & $\begin{array}{l}\text { Veneridae } \\
\text { CROMI022-19 }\end{array}$ \\
\hline $\begin{array}{l}\text { Veneridae indet. } 2 \text { juv. } \\
\text { (Veneridae) }\end{array}$ & $\begin{array}{l}\text { Austrovenus stutchburyi } \\
\text { (Veneridae; } 83.50 \text { ) }\end{array}$ & $\begin{array}{c}\text { BOLD:AEA5058 * } \\
(0.44 / 17.18)\end{array}$ & A & A & A & $\begin{array}{l}\text { Veneridae } \\
\text { CROMI023-19 }\end{array}$ \\
\hline $\begin{array}{l}\text { Veneridae indet. } 2 \text { juv. } \\
\text { (Veneridae) }\end{array}$ & $\begin{array}{l}\text { Austrovenus stutchburyi } \\
\text { (Veneridae; 83.89) }\end{array}$ & $\begin{array}{c}\text { BOLD:AEA5058 * } \\
(0.44 / 17.18)\end{array}$ & A & A & A & $\begin{array}{l}\text { Veneridae } \\
\text { CROMI024-19 }\end{array}$ \\
\hline $\begin{array}{l}\text { Veneridae indet. } 2 \text { juv. } \\
\text { (Veneridae) }\end{array}$ & $\begin{array}{l}\text { Austrovenus stutchburyi } \\
\text { (Veneridae; 83.89) }\end{array}$ & $\begin{array}{c}\text { BOLD:AEA5058 * } \\
(0.44 / 17.18)\end{array}$ & A & A & A & $\begin{array}{l}\text { Veneridae } \\
\text { CROMI025-19 }\end{array}$ \\
\hline $\begin{array}{l}\text { Veneridae indet. } 2 \text { juv. } \\
\text { (Veneridae) }\end{array}$ & $\begin{array}{l}\text { Austrovenus stutchburyi } \\
\text { (Veneridae; 83.74) }\end{array}$ & $\begin{array}{c}\text { BOLD:AEA5058 * } \\
(0.44 / 17.18)\end{array}$ & A & A & A & $\begin{array}{l}\text { Veneridae } \\
\text { CROMI026-19 }\end{array}$ \\
\hline $\begin{array}{l}\text { Veneridae indet. } 3 \text { juv. } \\
\text { (Veneridae) }\end{array}$ & $\begin{array}{l}\text { Kurtiella bidentata } \\
\text { (Lasaeidae; 85.34) }\end{array}$ & $\begin{array}{c}\text { BOLD:AEA5056 * } \\
\text { (N/A/15.14) }\end{array}$ & A & A & A & $\begin{array}{l}\text { Veneridae } \\
\text { CROMI028-19 }\end{array}$ \\
\hline $\begin{array}{l}\text { Veneridae indet. } 4 \text { juv. } \\
\text { (Veneridae) }\end{array}$ & $\begin{array}{l}\text { Kellia suborbicularis } \\
\text { (Lasaeidae; 80.26) } \\
\text { Petricola rugosa } \\
\text { (Veneridae; 79.51) }\end{array}$ & $\begin{array}{c}\text { BOLD:AEA5057 * } \\
(\mathrm{N} / \mathrm{A} / 18.97)\end{array}$ & A & A & A & $\begin{array}{l}\text { Veneridae } \\
\text { CROMI055-19 }\end{array}$ \\
\hline $\begin{array}{l}\text { POLYPLACOPHORA } \\
\text { Acanthochitona } \\
\text { fascicularis juv. } \\
\text { (Acanthochitonidae) }\end{array}$ & $\begin{array}{l}\text { Acanthochitona sp. } \\
\text { (Acanthochitonidae; } \\
88.77 \text { ) }\end{array}$ & $\begin{array}{c}\text { BOLD:AEA6823 * } \\
\text { (N/A/12.1) }\end{array}$ & A & A & A & $\begin{array}{l}\text { Acanthochitona fascicularis } \\
\text { (Acanthochitonidae)/ } \\
\text { CROMI037-19 }\end{array}$ \\
\hline
\end{tabular}

${ }^{*}$ BIN/OTU new for BOLD database; ${ }^{*}$ discordant BIN (composed of more than one morpho-species or multiple taxa names); ${ }^{* *}$ new addition for BOLD database. 
Table 2. Taxon list of mollusks isolated from C. officinalis turfs.

\begin{tabular}{|c|c|c|}
\hline GASTROPODA & c,e Odostomia plicata & ${ }^{\text {a }}$ Irus irus \\
\hline c,e Alvania cf. carinata & c Patella caerulea & b,e Lasaea cf. rubra \\
\hline d Alvania sp. 1 & c,e Phorcus turbinatus & a Lima lima \\
\hline a Alvania sp. 2 & a Pusilllina philippi & c,e Lithophaga lithophaga \\
\hline a,e Ammonicera fischeriana & a,e Rissoa splendida & d,e Lucinella sp. \\
\hline c Bittium reticulatum & d,e Rissoella sp. & ${ }^{\mathrm{c}}$ Musculus cf. costulatus \\
\hline a,e Crisilla beniamina & a,e Setia sp. & d,e Musculus sp. \\
\hline a Crisilla innominata & d Gastropoda indet. & ${ }^{\mathrm{c}}$ Mytilus galloprovincialis \\
\hline a,e Crisilla iunoniae & b Steromphala adriatica & b,e Striarca lactea \\
\hline c,e Crisilla cf. maculata & ${ }^{c}$ Vitreolina antiflexa & $\mathrm{d}$ Veneridae indet. 1 \\
\hline${ }^{\mathrm{c}}$ Eatonina cossurae & & ${ }^{\mathrm{d}}$ Veneridae indet. 2 \\
\hline d,e Eatonina sp. & BIVALVIA & $\mathrm{d}$ Veneridae indet. 3 \\
\hline${ }^{\mathrm{c}, \mathrm{e}}$ Episcomitra cornicula & b Cardita calyculata & $\mathrm{d}$ Veneridae indet. 4 \\
\hline c,e Gibbula cf. turbinoides & b,e Chama gryphoides & a Veneridae indet. 5 \\
\hline $\begin{array}{l}\text { a,e cf. Gibbula ardens } \\
\text { c }\end{array}$ & a Flexopecten glaber & \\
\hline${ }^{\mathrm{c}}$ Megastomia winfriedi & c,e Gregariella semigranata & POLYPLACOPHORA \\
\hline b Ocenebra cf. edwardsii & ${ }^{\mathrm{a}, \mathrm{e}}$ Hiatella rugosa & ${ }^{\mathrm{c}}$ Acanthochitona fascicularis \\
\hline
\end{tabular}

(a) identification based on morphology, (b) identification based on DNA barcoding, (c) identification based on morphology and DNA barcoding, (d) taxa from which DNA barcodes were obtained but no clear assignment to a species was possible, (e) species new compared to Buršić et al. [21].

Table 1 shows overall results of mollusks identification based on morphological features compared with the identification results based on similarity of obtained sequences with the sequences present in both databases (BOLD and GenBank), as well as the results of BIN-RESL and SDMs.

DNA barcoding confirmed species identification based on morphology for 18 specimens, which makes 33\% of the sequences. For eight specimens, making up 15\% of the sequences, the original morphological identification was refuted after comparison with the sequences available in the database. For these specimens, high similarity with the available sequences and the results from SDMs were crucial in correcting the original morphological determination. The gastropods in question were Steromphala adriatica, Gibbula cf. turbinoides and Ocenebra cf. edwardsii which were originally identified as cf. Gibbula ardens, cf. Gibbula ardens, and Muricopsis cristata, respectively. One of the specimens originally identified as cf. Gibbula ardens had $99.68 \%$ similarity with the Steromphala adriatica sequence, another one had $96.46 \%$ similarity with Gibbula turbinoides sequence, while a specimen originally identified as Muricopsis cristata had 100\% similarity with Ocenebra cf. edwardsii (Table 2). SDMs confirmed the assignments for S. adriatica and M. cristata, while for the third specimen the results of SDMs were not in concordance, and therefore this specimen was designated as G. cf. turbinoides. Bivalves in question were Lasaea cf. rubra, Mytilus galloprovincialis, Striarca lactea and Chama gryphoides. For the specimens originally identified as Mytilaster sp. and Mytilaster minimus it was later concluded that those specimens are in fact Mytilus galloprovincialis since their sequences had a 99\% similarity with the M. galloprovincialis sequence, further confirmed by SDMs. The species Striarca lacteal and Chama gryphoides were initially identified as Arca tetragona and Ostrea sp., respectively. A specimen originally identified as Arca tetragona had $98.62 \%$ similarity with the Striarca lactea sequence, while a specimen originally identified as Ostrea sp. had $99.85 \%$ similarity with the Chama gryphoides sequence, also confirmed by SDMs. A specimen initially morphologically identified as Lasaea adansoni was after analyses corrected to be Lasaea cf. rubra (Table 2).

For $52 \%$ of the specimens, DNA barcoding did not serve in identification to the species level due to the lack of available sequences in the BOLD and GenBank databases. In cases where morphological identification was also not reliable, the specimens were identified to the family or genus level with the help of a tree-based identification in the BOLD database. On the other hand, in cases of reliable morphological identification, newly sequenced specimens were submitted to the BOLD database as new species. In our study, there were 
nine such species, i.e., seven gastropod species and two bivalve species that represented new additions to the BOLD database. Gastropods were Megastomia winfriedi, Eatonina sp., Eatonina cossurae, Crisilla cf. maculata, Alvania cf. carinata, Vitreolina antiflexa and Odostomia plicata, and bivalves were Musculus cf. costulatus and Gregariella semigranata (Figure 2, Table 2).
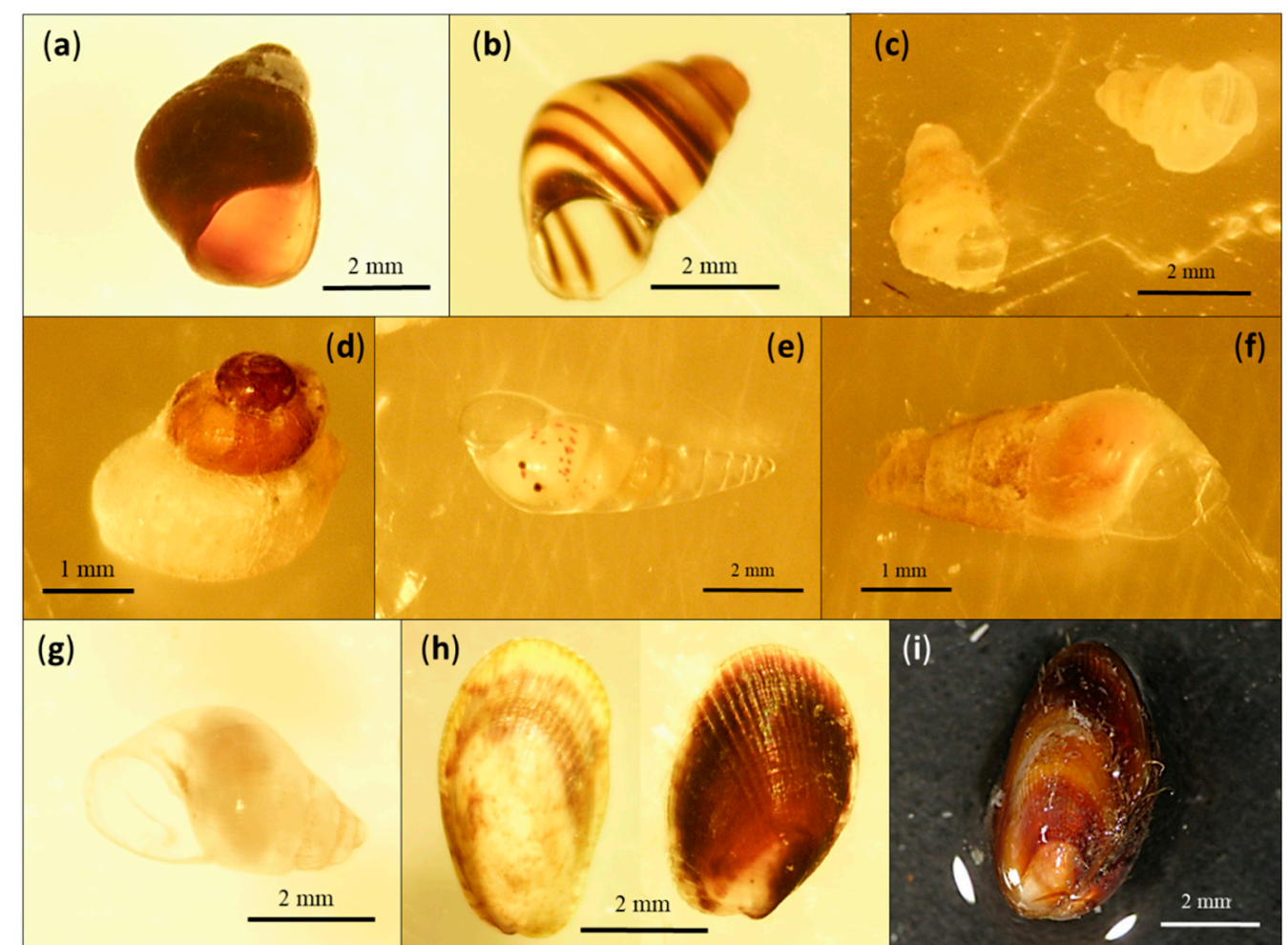

(h)

Figure 2. Species novel to the BOLD database: (a) Eatonina sp., (b) Eatonina cossurae, (c) Alvania cf. carinata, (d) Crisilla cf. maculata, (e) Vitreolina antiflexa, (f) Odostomia plicata, (g) Megastomia winfriedi, (h) Musculus cf. costulatus, (i) Gregariella semigranata.

In addition, the calculation of intraspecific and interspecific uncorrected pairwise distances ( $p$-distances) was performed for the specimens that were assigned to same species and/or same genera or families, in order to check the existence of the $3 \%$ similarity threshold, which is usually taken as the cut-off value for species separation in mollusks. Along with that, the existence of the barcoding gap was also checked. For gastropods, intraspecific $p$-distances calculation was conducted for five species which were represented with more than one individual. These are Crisilla cf. maculata, Phorcus turbinatus, Gibbula cf. turbinoides, Megastomia winfriedi and Rissoella sp. Table S4 shows that the maximum recorded intraspecific $p$-distance value was $2.32 \%$ for the species Rissoella sp., also within the $3 \%$ threshold.

Interspecific genetic $p$-distances for gastropods ranged from $14 \%$ to $35 \%$. Certain families were represented by several species, so $p$-distance values within the family, and in some cases within the genus, could also be recorded. For the family Rissoidae, which was represented with the genera Crisilla and Alvania, $p$-distance interspecific values ranged from $18 \%$ to $24 \%$. For the family Cingulopsidae and its only genus Eatonina, $p$-distance value was $24 \%$. Interspecific $p$-distance values within the family Trochidae (represented by the genera Phorcus, Gibbula and Steromphala) ranged from $14 \%$ to $16 \%$, while for the family Pyramidellidae (represented by the genera Megastomia and Odostomia) this value was 30\%.

For bivalves intraspecific $p$-distances calculation was performed for five species which were represented with more than one specimen. Species in question were Musculus cf. costulatus, Mytilus galloprovincialis, two species from the Veneridae family and Cardita 
calyculata. Tables S5 and S6 show that the 3\% threshold for intraspecific genetic distance was also met, with a maximum recorded intraspecific $p$-distance value of $2.72 \%$ for Mytilus galloprovincialis.

Interspecific genetic $p$-distances for bivalves ranged from $18 \%$ to $49 \%$. Mytilidae and Veneridae were represented by several specimens, so interspecific $p$-distance values within these families could also be calculated. For Mytilidae, which was represented with the genera Musculus, Mytilus, Gregariella and Lithophaga, values ranged from $21 \%$ to $40 \%$. Interspecific $p$-distance values for four species within the family Veneridae ranged from $18 \%$ to $36 \%$.

The obtained ranges of intra- and interspecific p-distances between the analyzed specimens of gastropods and bivalves do not overlap, thus corroborating the existence of the barcoding gap and further supporting species identification.

As a summary of all taxa recorded within our study, a list is provided in Table 2 with detailed information on the type of identification used (i.e., based on morphology and/or DNA barcoding). It is noteworthy to mention that twenty-two species were newly recorded for northern Adriatic Corallina turfs.

\section{Discussion}

Although molecular methods for specimen identification existed before the use of DNA barcoding, the method as such offers several major advantages. The most important advantage DNA barcoding brings is a form of standardization which allows comparison and verification of data between researchers [65]. However, the use of DNA barcoding was not intended as a method that will replace the very important and necessary taxonomy but as an addition that will complement it, which has shown to be helpful in many cases [30]. DNA barcoding has proven to be a useful tool in identifying mollusks. Given that in our study juvenile mollusks of a maximum body size up to only a few millimeters were predominant, determination according to morphological features was a significant challenge in most cases. Mollusks were often documented as a problematic group for DNA amplification [66], with various success rates of COI region amplification (e.g., 43\% for museum collection samples [67], 52\% for mollusks collected in Canada [66] and 59\% for samples of marine mollusks collected in the North Sea [29]. Therefore, the recorded success of amplified COI-barcode regions for $69 \%$ of specimens subjected to DNA barcoding in our study may be considered a satisfactory result. There are several suggested explanations for such variable success rates of DNA amplification for mollusks. Variations in mucopolysaccharide levels can often reduce the success of PCR amplification [68]. Polysaccharides present in tissue and mucus are considered a major problem because they co-precipitate with the DNA molecule and inhibit DNA polymerase activity [67]. This is most probably the main reason why the results of our study indicate better amplification when a 10-fold dilution of the second DNA eluate was used in the PCR reaction. In addition, living gastropods tend to retract and seal their shell with the operculum, which prevents the penetration of alcohol into the tissue, preventing proper fixation and conservation of the tissue, and consequently causing the degradation of genomic DNA which can hinder the amplification of the barcoding fragment. This is most likely explanation for the lack of sample amplification for some specimens in our study. Galindo et al. [69] suggested that a microwave oven can be used when extracting tissue from gastropod shells, since short exposure to the wavelength used by these devices facilitates tissue extraction, while at the same time the quality and quantity of the obtained DNA is not impaired. Another benefit of this method is that the intact gastropod shell can be preserved which is necessary for correct taxonomic identification and for proper storage as a barcode voucher.

The traditional approach for validating putative species using the DNA barcoding method is based on comparison of intra- and interspecific genetic distances [25,70]. There is much discussion in literature about which threshold is most appropriate, however data vary depending on the taxonomic group and species being investigated. Sweeney et al. [71] suggest that this range should be $2-4 \%$ for invertebrates, while the $3 \%$ threshold 
is frequently mentioned for marine mollusks [54-57]. Besides this, the existence of a clear barcoding gap, which is defined as ten times the ratio between the average interspecific and intraspecific distances [72], must also be taken into account. Another approach based on genetic distances relies on the absence of overlap between the values of the lowest interspecies variation and the highest intraspecific divergence [73]. However, many recent studies report great variation of intra- vs. interspecific distances in molluscan taxa [74-78], indicating that any a priori set threshold must be taken with caution and checked by alternative approaches for molecular identification.

A range of single-locus species delimitation methods are available which differ from each other in a number of aspects and which all take into account more than just the a priori set sequence distance thresholds, but instead employ various algorithms to identify minimal phylogenetic units (OTUs) within the phylogenetic species concept [79-85]. Molecular species delimitations have also been recently used in various studies of marine mollusks, mostly as part of integrative taxonomic approaches to species identification (e.g., [55-57], to mention just a few).

In our study, several methods were employed to classify questionable specimens as a particular species. For the calculation of COI genetic distances, the aforementioned threshold of $3 \%$ intraspecific variability was taken into account, as well as the barcoding gap. The average recorded intraspecific variability for gastropods was $1.25 \%$ (range $0-2.32 \%$ ) and for bivalves $0.7 \%$ (range $0-2.72 \%$ ), while the average interspecific variability for gastropods was $28 \%$ (range $14-35 \%$ ) and for bivalves $38 \%$ (range 18-49\%). The obtained intra- and interspecific $p$-distance values are comparable to range of values recorded in previous studies of mollusks where distances from $0 \%$ to $4.1 \%$ were obtained for intraspecific variability and from $4.3 \%$ to $34.4 \%$ for genetic divergence between different species [86-88]. Furthermore, our results confirm the existence of the barcoding gap, and show that there is no intra-/interspecies distance overlap for both gastropods and bivalves, even though this finding must be interpreted carefully since only few individuals per species were sampled.

Besides the obtained values of intraspecific variability and interspecific divergence, species delimitation methods were employed that allowed us the assignment of questionable specimens to particular species. This was precisely the case for Mytilus galloprovincialis, which was mostly represented by juvenile forms with only a few adult specimens. Juveniles are morphologically very similar to Mytilaster minimus, which had a controversial taxonomic history with many synonyms and subspecies variations [89]. However, based on evaluation of genetic distances and the results of SDMs, it was concluded that all newly sequenced specimens belong to the species Mytilus galloprovincialis. In addition to this species, a similar dilemma also occurred for specimens of Musculus costulatus and specimens belonging to family Veneridae, whose morphological features were not sufficiently informative. Integration of employed molecular methods ultimately allowed their classification to particular OTUs with a significant level of confidence, although the specimens of Veneridae could not be identified to species level due to lack of data in databases.

Correct specimen identification using the DNA barcoding method requires a comprehensive database containing sequences of the same species that is being identified. The lack of reference sequences was precisely the reason why certain specimens from our study were not identified to the species level. In particular, this applies to one gastropod species that was uploaded to BOLD simply as Gastropoda (BOLD Process ID CROMI007-19 and GenBank Accession number MT920137). According to morphology, these specimens were identified as Sinezona cingulata, which is not currently present in the BOLD database and GenBank. However, since the similarity of our specimen's sequence with the only congeneric species present in GenBank (S. confusa [90]) was below 65\%, we did not make a new entry for BOLD database under the name $S$. cingulata. However, in some cases it was possible to identify the specimen up to the genus or family level (as in the case of Veneridae specimens). Yet another category are several specimens for which incongruent results of species delimitation methods were obtained, but nevertheless we were confident in our identification according to morphological features. This applies for example to Cardita 
calyculata and Bittium reticulatum. When various developmental stages were present, such as in the case of Cardita calyculata, we were able to identify the specimens that already begun having morphological features crucial for identification (Figure 3). Juvenile mollusks are often morphologically very different from adult individuals, so DNA barcoding is increasingly used by taxonomists as a tool to avoid confusion and misidentification of specimens. Molecular identification of juvenile individuals can help in understanding the life cycle of individual species [26] and in the early detection of invasive species [91].

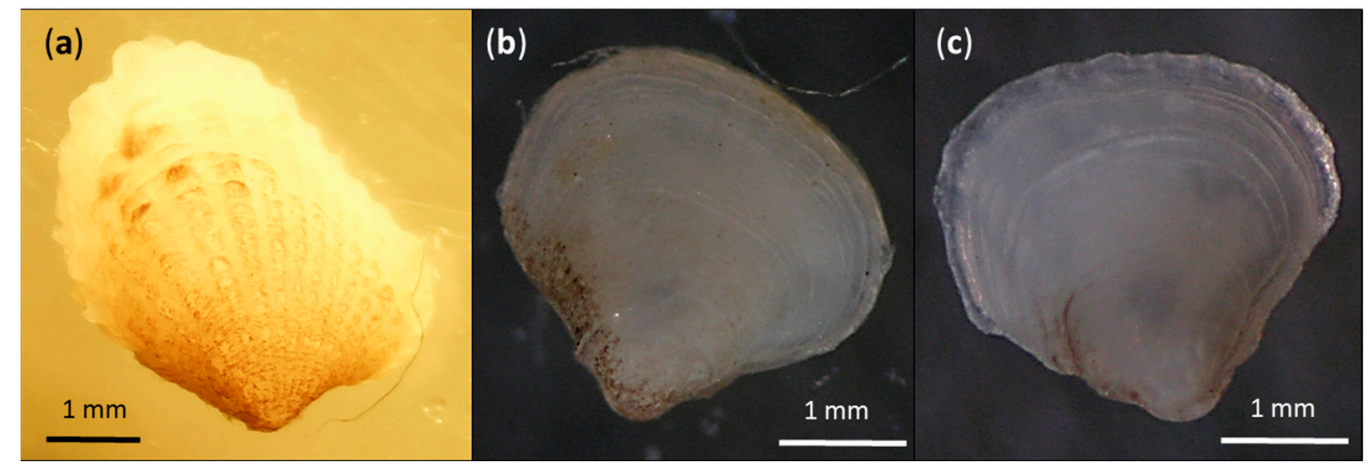

Figure 3. Different developmental stages of Cardita calyculata with morphological features that vary for individuals with only a few millimeters difference in size. BOLD Process IDs and GenBank Accession numbers are: (a) CROMI035-19, MT920126, (b) CROMI020-19, MT920128, (c) CROMI01719, MT920129. In Table S5: $(\mathbf{a})=$ Species $3 c,(\mathbf{b})=$ Species $3 e$ and $(\mathbf{c})=$ Species $3 a$.

In cases of taxa which most probably represent species complexes or cryptic species, which are quite common in mollusks $[75,76,87,89]$, species delimitation methods and BINRESL can efficiently point to these taxonomic problems. Several instances of such complex taxa have also been noticed in this study, through appearance of the same species names in two (or even several) clearly separate BINs. e.g., Ocenebra edwardsi, Gibbula turbinoides and Striarca lactaea appear in two separate BINs each, while the most striking example is Mytilus galloprovinciallis which is present in as much as 21 BINs in BOLD database. Another quite often encountered issue in BOLD is related to cases of (most probably) erroneous initial morphological determinations which remain unnoticed and which result in discordant BINs in BOLD database, i.e., BINs composed of specimens with different species names. In our work we noticed two cases of such discordance, namely BINs containing our specimens of S. adriatica and M. galloprovincialis.

Existing database sequences are therefore a key part of DNA barcoding for specimen identification. A reliable database of verified sequences is necessary to compare newly obtained sequences and possibly identify questionable individuals [92]. Without reference sequences with vouchers whose authenticity and accuracy of taxonomic identification have been confirmed by qualified expert taxonomists, it is not possible to exploit the full potential of DNA barcoding. However, data entry into the BOLD database far exceeds the speed of their verification, so this verification process is the bottleneck of the entire initiative [92]. Nevertheless, this situation is improving daily since many researchers are contributing to the BOLD database.

A comparison of mollusk species isolated from C. officinalis turfs with previously recorded species conducted throughout the world confirms this algal settlement as a biodiversity reservoir for marine mollusks. Most commonly recorded genera for gastropods are Alvania, Eatonina, Odostomia, Rissoa, Rissoella and the family Rissoidae in general, and for bivalves Hiatella, Lasaea, Musculus and Mytilus [2,12-21,23,93-95] which were all recorded in considerable numbers in our study as well. Even though C. officinalis turfs have been investigated for years, there are still many unknowns regarding its settlements, which is further substantiated by the fact that we identified one gastropod genus (Episcomitra) and three bivalve genera (Gregariella, Lucinella, Striarca) that were not documented in previous studies. Even when compared with the Buršić et al. [21] study, which was conducted in 
the same research areas as our study, we identified 14 new gastropod species and 8 new bivalve species in the $C$. officinalis settlements in the northern Adriatic (Table 2). Regarding the biodiversity of marine invertebrates in the Adriatic Sea, our research also contributed to the BOLD database, given that nine newly sequenced mollusk species were added to the database. However, having in mind that DNA barcoding relies on a single molecular marker and that sequences and taxon samplings in public databases are far from dense or suitable enough for species identification in many taxa, additional investigations with larger sample size are needed in order to gain a full picture of biodiversity in this realm.

\section{Conclusions}

Our results of 46 identified mollusk species confirm C. officinalis settlements as important areas for coastal biodiversity. Based on the results of this study and given that mollusks isolated within the C. officinalis turfs were predominantly specimens that were very difficult to determine only by morphological features, DNA barcoding greatly helped as an additional tool in specimen identification. In the case where it was not possible to identify a specimen down to the species level or when it was not possible to state with certainty whether particular specimens were the same or different species, DNA barcoding proved to be the most appropriate option in resolving these dilemmas. The combination of classical taxonomic methods and DNA barcoding as specimen identification is therefore recommended in resolving potential doubts and difficulties encountered by taxonomists as successfully as possible.

Supplementary Materials: The following are available online at https:/ / www.mdpi.com/article/10 .3390/d13050196/s1, Table S1: Specimens used in analysis with assigned species name, BOLD Process ID number, GenBank Accession number and Inventory numbers in the Invertebrates DNA Barcode collection at the Juraj Dobrila University of Pula; Supplementary S2: Alignment datasets; Supplementary S3: Maximum likelihood (ML) trees; Table S4: Inter- and intraspecific genetic p-distances of the mitochondrial cytochrome oxidase I (cox-1) gene fragments recorded for gastropod species (numbers in bold show intraspecific p-distance values); Table S5: Inter- and intraspecific genetic p-distances of the mitochondrial cytochrome oxidase I (cox-1) gene fragments recorded for bivalve species $M$. costulatus, M. galloprovincialis and C. calyculata (numbers in bold show intraspecific p-distance values); Table S6: Inter- and intraspecific genetic p-distances of the mitochondrial cytochrome oxidase I (cox-1) gene fragments recorded for Veneridae (numbers in bold show intraspecific p-distance values).

Author Contributions: Conceptualization, M.B., B.B.M. and L.I.; Data Curation, M.B. and B.B.M.; Formal Analysis, M.B. and B.B.M.; Funding Acquisition, M.K.; Investigation, M.B., L.I., A.J. and M.A.P.; Methodology, M.B. and B.B.M.; Project Administration, M.K.; Resources, M.K., M.Š., A.J. and M.A.P.; Writing-Original Draft Preparation, M.B. and B.B.M.; Writing-Review \& Editing, M.B., B.B.M., L.I., A.J., M.Š. and L.N. All authors have read and agreed to the published version of the manuscript.

Funding: This research was funded by the Croatian Science Foundation under the project IP-2016-069988 (“DNA Barcoding of Diversity of Croatian Fauna”, P.I. Prof. M.K.).

Institutional Review Board Statement: Not applicable.

Informed Consent Statement: Not applicable.

Data Availability Statement: The mtDNA COI-5P sequences are submitted to BOLD and GenBank databases.

Conflicts of Interest: The authors declare no conflict of interest.

\section{References}

1. Williamson, C.J.; Perkins, R.; Voller, M.; Yallop, M.L.; Brodie, J. The Regulation of Coralline Algal Physiology, an in situ Study of Corallina officinalis (Corallinales, Rhodophyta). Biogeosciences 2017, 14, 4485-4498. [CrossRef]

2. Liuzzi, M.G.; Gappa, J.L. Macrofaunal Assemblages Associated with Coralline Turf: Species Turnover and Changes in Structure at Different Spatial Scales. Mar. Ecol. Prog. Ser. 2008, 363, 147-156. [CrossRef] 
3. Hofmann, L.C.; Yildiz, G.; Hanelt, D.; Bischof, K. Physiological Responses of the Calcifying Rhodophyte, Corallina officinalis (L.), to Future $\mathrm{CO}_{2}$ Levels. Mar. Biol. 2012, 159, 783-792. [CrossRef]

4. Rendina, F.; Bouchet, P.J.; Appolloni, L.; Russo, G.F.; Sandulli, R.; Kolzenburg, R.; Putra, A.; Ragazzola, F. Physiological Response of the Coralline Alga Corallina officinalis L. to Both Predicted Long-Term Increases in Temperature and Short-Term Heatwave Events. Mar. Environ. Res. 2019, 150, 104764. [CrossRef]

5. Nikolić, V.; Žuljević, A.; Mangialajo, L.; Antolić, B.; Kušpilić, G.; Ballesteros, E. Cartography of Littoral Rocky-Shore Communities (CARLIT) as a Tool for Ecological Quality Assessment of Coastal Waters in the Eastern Adriatic Sea. Ecol. Indic. 2013, 34, 87-93. [CrossRef]

6. Iveša, L.; Lyons, D.M.; Devescovi, M. Assessment of the Ecological Status of North-Eastern Adriatic Coastal Waters (Istria, Croatia) Using Macroalgal Assemblages for the European Union Water Framework Directive. Aquat. Conserv. Mar. Freshw. Ecosyst. 2009, 19, 14-23. [CrossRef]

7. Kelaher, B.P. Changes in Habitat Complexity Negatively Affect Diverse Gastropod Assemblages in Coralline Algal Turf. Oecologia 2003, 135, 431-441. [CrossRef] [PubMed]

8. Kelaher, B.P.; Castilla, J.C.; Seed, R. Intercontinental Test of Generality for Spatial Patterns among Diverse Molluscan Assemblages in Coralline Algal Turf. Mar. Ecol. Prog. Ser. 2004, 271, 221-231. [CrossRef]

9. Matias, M.G.; Underwood, A.J.; Coleman, R.A. Interactions of Components of Habitats Alter Composition and Variability of Assemblages. J. Anim. Ecol. 2007, 76, 986-994. [CrossRef]

10. Matias, M.G.; Arenas, F.; Rubal, M.; Pinto, I.S. Macroalgal Composition Determines the Structure of Benthic Assemblages Colonizing Fragmented Habitats. PLoS ONE 2015, 10, e0142289. [CrossRef]

11. Lavender, J.T.; Dafforn, K.A.; Bishop, M.J.; Johnston, E.L. Small-Scale Habitat Complexity of Artificial Turf Influences the Development of Associated Invertebrate Assemblages. J. Exp. Mar. Biol. Ecol. 2017, 492, 105-112. [CrossRef]

12. Dommasnes, A. On the Fauna of Corallina officinalis L. in Western Norway. Sarsia 1969, 38, 71-86. [CrossRef]

13. Akioka, H.; Baba, M.; Masaki, T.; Johansen, H.W. Rocky Shore Turfs Dominated by Corallina (Corallinales, Rhodophyta) in Northern Japan. Phycol. Res. 1999, 47, 199-206. [CrossRef]

14. Kelaher, B.P.; Chapman, M.G.; Underwood, A.J. Spatial Patterns of Diverse Macrofaunal Assemblages in Coralline Turf and Their Associations with Environmental Variables. J. Mar. Biol. Assoc. UK 2001, 81, 917-930. [CrossRef]

15. Kelaher, B.P.; Carlos Castilla, J. Habitat Characteristics Influence Macrofaunal Communities in Coralline Turf More than Mesoscale Coastal Upwelling on the Coast of Northern Chile. Estuar. Coast. Shelf Sci. 2005, 63, 155-165. [CrossRef]

16. Bussell, J.A.; Lucas, I.A.N.; Seed, R. Patterns in the Invertebrate Assemblage Associated with Corallina officinalis in Tide Pools. J. Mar. Biol. Assoc. UK 2007, 87, 383-388. [CrossRef]

17. Kelaher, B.P.; Castilla, J.C.; Prado, L.; York, P.; Schwindt, E.; Bortolus, A. Spatial Variation in Molluscan Assemblages from Coralline Turfs of Argentinean Patagonia. J. Molluscan Stud. 2007, 73, 139-146. [CrossRef]

18. Kelaher, B.P.; Castilla, J.C.; Prado, L. Is There Redundancy in Bioengineering for Molluscan Assemblages on the Rocky Shores of Central Chile? Rev. Chil. Hist. Nat. 2007, 80, 173-186. [CrossRef]

19. Berthelsen, A.K.; Hewitt, J.E.; Taylor, R.B. Biological Traits and Taxonomic Composition of Invertebrate Assemblages Associated with Coralline Turf along an Environmental Gradient. Mar. Ecol. Prog. Ser. 2015, 530, 15-27. [CrossRef]

20. Berthelsen, A.K.; Hewitt, J.E.; Taylor, R.B. Coralline Turf-Associated Fauna Are Affected More by Spatial Variability than by Host Species Identity. Mar. Biodiv 2015, 45, 689-699. [CrossRef]

21. Buršić, M.; Iveša, L.; Jaklin, A.; Arko Pijevac, M. A Preliminary Study on the Diversity of Invertebrates Associated with Corallina officinalis Linnaeus in Southern Istrian Peninsula. Acta Adriat. Int. J. Mar. Sci. 2019, 60, 127-135. [CrossRef]

22. Magill, C.L.; Maggs, C.A.; Johnson, M.P.; O'Connor, N. Sustainable Harvesting of the Ecosystem Engineer Corallina officinalis for Biomaterials. Front. Mar. Sci. 2019, 6. [CrossRef]

23. Wilson, B.; Hayek, L.-A.C. Calcareous Meiofauna Associated with the Calcareous Alga Corallina officinalis on Bedrock and Boulder-Field Shores of Ceredigion, Wales, UK. J. Mar. Biol. Assoc. UK 2020, 100, 1205-1217. [CrossRef]

24. Lehmann, T.; Spelda, J.; Melzer, R.; Buršić, M. Pycnogonida (Arthropoda) from Northern Adriatic Corallina officinalis Linnaeus, 1758 Belts. Mediterr. Mar. Sci. 2021, 22, 102-107. [CrossRef]

25. Hebert, P.D.N.; Cywinska, A.; Ball, S.L.; deWaard, J.R. Biological Identifications through DNA Barcodes. Proc. Biol. Sci. 2003, 270, 313-321. [CrossRef]

26. Boyer, S.L.; Howe, A.A.; Juergens, N.W.; Hove, M.C. A DNA-Barcoding Approach to Identifying Juvenile Freshwater Mussels (Bivalvia:Unionidae) Recovered from Naturally Infested Fishes. J. N. Am. Benthol. Soc. 2011, 30, 182-194. [CrossRef]

27. Meyer, R.; Weis, A.; Melzer, R.R. Decapoda of Southern Chile: DNA Barcoding and Integrative Taxonomy with Focus on the Genera Acanthocyclus and Eurypodius. Syst. Biodivers. 2013, 11, 389-404. [CrossRef]

28. Schander, C.; Willassen, E. What Can Biological Barcoding Do for Marine Biology? Mar. Biol. Res. 2005, 1, 79-83. [CrossRef]

29. Barco, A.; Raupach, M.J.; Laakmann, S.; Neumann, H.; Knebelsberger, T. Identification of North Sea Molluscs with DNA Barcoding. Mol. Ecol. Resour. 2016, 16, 288-297. [CrossRef]

30. Trivedi, S.; Aloufi, A.A.; Ansari, A.A.; Ghosh, S.K. Role of DNA Barcoding in Marine Biodiversity Assessment and Conservation: An Update. Saudi J. Biol. Sci. 2016, 23, 161-171. [CrossRef] 
31. Ramirez, J.L.; Rosas-Puchuri, U.; Cañedo, R.M.; Alfaro-Shigueto, J.; Ayon, P.; Zelada-Mázmela, E.; Siccha-Ramirez, R.; VelezZuazo, X. DNA Barcoding in the Southeast Pacific Marine Realm: Low Coverage and Geographic Representation despite High Diversity. PLoS ONE 2020, 15, e0244323. [CrossRef]

32. Yang, C.; Lv, Q.; Zhang, A. Sixteen Years of DNA Barcoding in China: What Has Been Done? What Can Be Done? Front. Ecol. Evol. 2020, 8. [CrossRef]

33. Tillin, H.M.; Budd, G. Coralline Crust-Dominated Shallow Eulittoral Rockpools; Marine Life Information Network: Biology and Sensitivity Key Information Reviews [on-line]; Marine Biological Association of the United Kingdom: Plymouth, UK, 2016.

34. Nordsieck, F. Die Europäischen Meeres-Gehäuseschnecken (Prosobranchia): Vom Eismeer bis Kapverden, Mittelmeer und Schwarzes Meer; Gustav Fischer Verlag: Stuttgart, Germany, 1968.

35. Nordsieck, F. Die Europaischen Meeresmuscheln (Bivalvia): Vom Eismeer bis Kapverden, Mittelmeer und Schwarzes Meer; Gustav Fischer Verlag: Stuttgart, Germany, 1969.

36. Parenzan, P. Carta D'identità Delle Conchiglie del Mediterraneo. Vol. I. Gasteropodi; Bios Taras: Taranto, Italy, 1970.

37. Parenzan, P. Carta D'identità Delle Conchiglie del Mediterraneo. Vol. II. Bivalvi, Prima Parte; Bios Taras: Taranto, Italy, 1974.

38. Sabelli, B.; Giannuzzi-Savelli, R.; Bedulli, D. Catalogo Annotato dei Molluschi Marini del Mediterraneo. Vol. I; Libreria Naturalistica Bolognese: Bologna, Italy, 1990.

39. Poppe, G.T.; Goto, Y. European Seashells Vol. II (Scaphopoda, Bivalvia, Cephalopoda); Verlag Christa Hemmen: Wiesbaden, Germany, 1993.

40. Gianuzzi-Savelli, R.; Pusateri, F.; Palmeri, A.; Ebreo, C. Atlante Delle Conchiglie Marine Del Mediterraneo; La Conchiglia: Roma, Italy, 1996.

41. Gofas, S.; Moreno, D.; Salas, C. (Eds.) Moluscos Marinos de Andalucía. Vol. I; Universidad de Málaga: Málaga, Spain, 2011; ISBN 978-84-9747-356-9.

42. Gofas, S.; Moreno, D.; Salas, C. (Eds.) Moluscos Marinos de Andalucía. Vol. II; Universidad de Málaga: Málaga, Spain, 2011; ISBN 978-84-9747-356-9.

43. WoRMS -World Register of Marine Species. Available online: http://www.marinespecies.org/ (accessed on 30 March 2021).

44. Folmer, O.; Black, M.; Wr, H.; Lutz, R.; Vrijenhoek, R. DNA Primers for Amplification of Mitochondrial Cytochrome C Oxidase Subunit I from Diverse Metazoan Invertebrates. Mol. Mar. Biol. Biotechnol. 1994, 3, 294-299. [PubMed]

45. Geller, J.; Meyer, C.; Parker, M.; Hawk, H. Redesign of PCR Primers for Mitochondrial Cytochrome c Oxidase Subunit I for Marine Invertebrates and Application in All-Taxa Biotic Surveys. Mol. Ecol. Resour. 2013, 13, 851-861. [CrossRef]

46. Lobo, J.; Costa, P.M.; Teixeira, M.A.L.; Ferreira, M.S.G.; Costa, M.H.; Costa, F.O. Enhanced Primers for Amplification of DNA Barcodes from a Broad Range of Marine Metazoans. BMC Ecol. 2013, 13, 34. [CrossRef] [PubMed]

47. Duda, M.; Schindelar, J.; Macek, O.; Eschner, A.; Kruckenhauser, L. First Record of Trochulus clandestinus (Hartmann, 1821) in Austria (Gastropoda: Eupulmonata: Hygromiidae). Malacol. Bohemoslov. 2017, 16, 37-43.

48. Hall, T.A. BioEdit: A User-Friendly Biological Sequence Alignment Editor and Analysis Program for Windows 95/98/NT. Nucleic Acids Symp. Ser. 1999, 41, 95-98.

49. Kearse, M.; Moir, R.; Wilson, A.; Stones-Havas, S.; Cheung, M.; Sturrock, S.; Buxton, S.; Cooper, A.; Markowitz, S.; Duran, C.; et al. Geneious Basic: An Integrated and Extendable Desktop Software Platform for the Organization and Analysis of Sequence Data. Bioinformatics 2012, 28, 1647-1649. [CrossRef]

50. Madeira, F.; Park, Y.; Lee, J.; Buso, N.; Gur, T.; Madhusoodanan, N.; Basutkar, P.; Tivey, A.R.N.; Potter, S.C.; Finn, R.D.; et al. The EMBL-EBI Search and Sequence Analysis Tools APIs in 2019. Nucleic Acids Res. 2019, 47, W636-W641. [CrossRef]

51. Ratnasingham, S.; Hebert, P.D.N. BOLD: The Barcode of Life Data System. Mol. Ecol. Notes 2007, 7, 355-364. [CrossRef]

52. Sayers, E.W.; Beck, J.; Bolton, E.E.; Bourexis, D.; Brister, J.R.; Canese, K.; Comeau, D.C.; Funk, K.; Kim, S.; Klimke, W.; et al. Database Resources of the National Center for Biotechnology Information. Nucleic Acids Res. 2021, 49, D10-D17. [CrossRef] [PubMed]

53. Kumar, S.; Stecher, G.; Li, M.; Knyaz, C.; Tamura, K. MEGA X: Molecular Evolutionary Genetics Analysis across Computing Platforms. Mol. Biol. Evol. 2018, 35, 1547-1549. [CrossRef] [PubMed]

54. Meyer, C.P.; Paulay, G. DNA Barcoding: Error Rates Based on Comprehensive Sampling. PLoS Biol. 2005, 3, e422. [CrossRef] [PubMed]

55. Audzijonyte, A.; Krylova, E.M.; Sahling, H.; Vrijenhoek, R.C. Molecular Taxonomy Reveals Broad Trans-Oceanic Distributions and High Species Diversity of Deep-Sea Clams (Bivalvia: Vesicomyidae: Pliocardiinae) in Chemosynthetic Environments. Syst. Biodivers. 2012, 10, 403-415. [CrossRef]

56. Breure, A.S.H. Caribbean Bulimulus Revisited: Physical Moves and Molecular Traces (Mollusca, Gastropoda, Bulimulidae). PeerJ 2016, 4, e1836. [CrossRef]

57. Liu, J.; Zhang, H. DNA Barcoding for Species Identification in Deep-Sea Clams (Mollusca: Bivalvia: Vesicomyidae). Mitochondrial DNA Part. A 2018, 29, 1165-1173. [CrossRef] [PubMed]

58. Ratnasingham, S.; Hebert, P.D.N. A DNA-Based Registry for All Animal Species: The Barcode Index Number (BIN) System. PLoS ONE 2013, 8, e66213. [CrossRef]

59. Zhang, J.; Kapli, P.; Pavlidis, P.; Stamatakis, A. A General Species Delimitation Method with Applications to Phylogenetic Placements. Bioinformatics 2013, 29, 2869-2876. [CrossRef] 
60. Puillandre, N.; Brouillet, S.; Achaz, G. ASAP: Assemble Species by Automatic Partitioning. Mol. Ecol. Resour. 2021, 21, 609-620. [CrossRef]

61. Puillandre, N.; Lambert, A.; Brouillet, S.; Achaz, G. ABGD, Automatic Barcode Gap Discovery for Primary Species Delimitation: Abgd, automatic barcode gap discovery. Mol. Ecol. 2012, 21, 1864-1877. [CrossRef]

62. Katoh, K.; Rozewicki, J.; Yamada, K.D. MAFFT Online Service: Multiple Sequence Alignment, Interactive Sequence Choice and Visualization. Brief. Bioinform. 2019, 20, 1160-1166. [CrossRef] [PubMed]

63. Guindon, S.; Dufayard, J.-F.; Lefort, V.; Anisimova, M.; Hordijk, W.; Gascuel, O. New Algorithms and Methods to Estimate Maximum-Likelihood Phylogenies: Assessing the Performance of PhyML 3.0. Syst. Biol. 2010, 59, 307-321. [CrossRef] [PubMed]

64. Lefort, V.; Longueville, J.-E.; Gascuel, O. SMS: Smart Model Selection in PhyML. Mol. Biol. Evol. 2017, 34, 2422-2424. [CrossRef] [PubMed]

65. Radulovici, A.E.; Archambault, P.; Dufresne, F. DNA Barcodes for Marine Biodiversity: Moving Fast Forward? Diversity 2010, 2, 450-472. [CrossRef]

66. Layton, K.K.S.; Martel, A.L.; Hebert, P.D. Patterns of DNA Barcode Variation in Canadian Marine Molluscs. PLoS ONE 2014, 9 , e95003. [CrossRef] [PubMed]

67. Jaksch, K.; Eschner, A.; Rintelen, T.V.; Haring, E. DNA Analysis of Molluscs from a Museum Wet Collection: A Comparison of Different Extraction Methods. BMC Res. Notes 2016, 9, 348. [CrossRef]

68. Knebelsberger, T.; Stöger, I. DNA Extraction, Preservation, and Amplification. Methods Mol. Biol 2012, 858, 311-338. [CrossRef]

69. Galindo, L.A.; Puillandre, N.; Strong, E.E.; Bouchet, P. Using Microwaves to Prepare Gastropods for DNA Barcoding. Mol. Ecol. Resour. 2014, 14, 700-705. [CrossRef]

70. Hebert, P.D.N.; Penton, E.H.; Burns, J.M.; Janzen, D.H.; Hallwachs, W. Ten Species in One: DNA Barcoding Reveals Cryptic Species in the Neotropical Skipper Butterfly Astraptes Fulgerator. Proc. Natl. Acad. Sci. USA 2004, 101, 14812-14817. [CrossRef]

71. Sweeney, B.W.; Battle, J.M.; Jackson, J.K.; Dapkey, T. Can DNA Barcodes of Stream Macroinvertebrates Improve Descriptions of Community Structure and Water Quality? J. N. Am. Benthol. Soc. 2011, 30, 195-216. [CrossRef]

72. Hebert, P.D.N.; Stoeckle, M.Y.; Zemlak, T.S.; Francis, C.M. Identification of Birds through DNA Barcodes. PLoS Biol. 2004,2 , e312. [CrossRef] [PubMed]

73. Meier, R.; Zhang, G.; Ali, F. The Use of Mean Instead of Smallest Interspecific Distances Exaggerates the Size of the “Barcoding Gap" and Leads to Misidentification. Syst. Biol. 2008, 57, 809-813. [CrossRef] [PubMed]

74. Sun, S.; Li, Q.; Kong, L.; Yu, H.; Zheng, X.; Yu, R.; Dai, L.; Sun, Y.; Chen, J.; Liu, J.; et al. DNA Barcoding Reveal Patterns of Species Diversity among Northwestern Pacific Molluscs. Sci. Rep. 2016, 6, 33367. [CrossRef] [PubMed]

75. Affenzeller, S.; Haar, N.; Steiner, G. Revision of the Genus Complex Gibbula: An Integrative Approach to Delineating the Eastern Mediterranean Genera Gibbula Risso, 1826, Steromphala Gray, 1847, and Phorcus Risso, 1826 Using DNA-Barcoding and Geometric Morphometrics (Vetigastropoda, Trochoidea). Org. Divers. Evol. 2017, 17, 789-812. [CrossRef]

76. Barco, A.; Aissaoui, C.; Houart, R.; Bonomolo, G.; Crocetta, F.; Oliverio, M. Revision of the Ocinebrina aciculata Species Complex (Mollusca: Gastropoda: Muricidae) in the Northeastern Atlantic Ocean and Mediterranean Sea. J. Molluscan Stud. 2018, 84, 19-29. [CrossRef]

77. Barroso, C.X.; de Freitas, J.E.P.; Matthews-Cascon, H.; Bezerra, L.E.A.; Lotufo, T.M.d.C. Molecular Evidences Confirm the Taxonomic Separation of Two Sympatric Congeneric Species (Mollusca, Gastropoda, Neritidae, Neritina). ZooKeys 2020, 904, 117-130. [CrossRef]

78. Ran, K.; Li, Q.; Qi, L.; Li, W.; Kong, L. DNA Barcoding for Identification of Marine Gastropod Species from Hainan Island, China. Fish. Res. 2020, 225, 105504. [CrossRef]

79. Fujisawa, T.; Barraclough, T.G. Delimiting Species Using Single-Locus Data and the Generalized Mixed Yule Coalescent Approach: A Revised Method and Evaluation on Simulated Data Sets. Syst. Biol. 2013, 62, 707-724. [CrossRef] [PubMed]

80. Zhang, C.; Rannala, B.; Yang, Z. Bayesian Species Delimitation Can Be Robust to Guide-Tree Inference Errors. Syst. Biol. 2014, 63, 993-1004. [CrossRef]

81. Dellicour, S.; Flot, J.-F. Delimiting Species-Poor Data Sets Using Single Molecular Markers: A Study of Barcode Gaps, Haplowebs and GMYC. Syst. Biol. 2015, 64, 900-908. [CrossRef]

82. Yang, Z. The BPP Program for Species Tree Estimation and Species Delimitation. Curr. Zool. 2015, 61, 854-865. [CrossRef]

83. Mallo, D.; De Oliveira Martins, L.; Posada, D. SimPhy: Phylogenomic Simulation of Gene, Locus, and Species Trees. Syst. Biol. 2016, 65, 334-344. [CrossRef]

84. Jackson, N.D.; Carstens, B.C.; Morales, A.E.; O’Meara, B.C. Species Delimitation with Gene Flow. Syst. Biol. 2017, 66, 799-812. [CrossRef]

85. Luo, A.; Ling, C.; Ho, S.Y.W.; Zhu, C.-D. Comparison of Methods for Molecular Species Delimitation Across a Range of Speciation Scenarios. Syst. Biol. 2018, 67, 830-846. [CrossRef] [PubMed]

86. Feng, Y.; Li, Q.; Kong, L.; Zheng, X. DNA Barcoding and Phylogenetic Analysis of Pectinidae (Mollusca: Bivalvia) Based on Mitochondrial COI and 16S RRNA Genes. Mol. Biol. Rep. 2011, 38, 291-299. [CrossRef] [PubMed]

87. Barco, A.; Evans, J.; Schembri, P.J.; Taviani, M.; Oliverio, M. Testing the Applicability of DNA Barcoding for Mediterranean Species of Top-Shells (Gastropoda, Trochidae, Gibbula s.1.). Mar. Biol. Res. 2013, 9, 785-793. [CrossRef] 
88. Furfaro, G.; Modica, M.V.; Oliverio, M.; Mariottini, P. A DNA-Barcoding Approach to the Phenotypic Diversity of Mediterranean Species of Felimare Ev. Marcus \& Er. Marcus, 1967 (Mollusca: Gastropoda), with a Preliminary Phylogenetic Analysis. Ital. J. Zool. 2016, 83, 195-207. [CrossRef]

89. Pejovic, I.; Ardura, A.; Miralles, L.; Arias, A.; Borrell, Y.J.; Garcia-Vazquez, E. DNA Barcoding for Assessment of Exotic Molluscs Associated with Maritime Ports in Northern Iberia. Mar. Biol. Res. 2016, 12, 168-176. [CrossRef]

90. Giribet, G.; Wheeler, W. On Bivalve Phylogeny: A High-Level Analysis of the Bivalvia (Mollusca) Based on Combined Morphology and DNA Sequence Data. Invertebr. Biol. 2002, 121, 271-324. [CrossRef]

91. Borrell, Y.J.; Miralles, L.; Huu, H.D.; Mohammed-Geba, K.; Garcia-Vazquez, E. DNA in a Bottle-Rapid Metabarcoding Survey for Early Alerts of Invasive Species in Ports. PLoS ONE 2017, 12, e0183347. [CrossRef] [PubMed]

92. Taylor, H.R.; Harris, W.E. An Emergent Science on the Brink of Irrelevance: A Review of the Past 8 Years of DNA Barcoding. Mol. Ecol. Resour. 2012, 12, 377-388. [CrossRef]

93. Bonsdorff, E. Effects of Experimental Oil Exposure on the Fauna Associated with Corallina officinalis L. in Intertidal Rock Pools. Sarsia 1983, 68, 149-155. [CrossRef]

94. Grahame, J.; Hanna, F.S. Factors Affecting the Distribution of the Epiphytic Fauna of Corallina officinalls (L.) on an Exposed Rocky Shore. Ophelia 1989, 30, 113-129. [CrossRef]

95. Olabarria, C.; Chapman, M.G. Comparison of Patterns of Spatial Variation of Microgastropods between 2 Contrasting Intertidal Habitats. Mar. Ecol. Prog. Ser. Mar. Ecol. Progr Ser. 2001, 220, 201-211. [CrossRef] 